\title{
Application analysis of shale gas core hyperspectral in weican-1 well
}

\author{
Liu Pengfei ${ }^{1 *}$, Tong Peng ${ }^{2}$, Zhao Yinjun $^{1}$, Guo tianxu ${ }^{3}$, Zhang hongda ${ }^{3}$ \\ ${ }^{1}$ National Key Laboratory of Remote Sensing Information and Image Analysis Technology, Beijing Research Institute of Uranium \\ Geology, Beijing 100029, China \\ ${ }^{2}$ Railway Engineering Consulting Group CO.,LTD. Beijing 100055, China \\ ${ }^{3}$ China Geological Survey Oil and Gas Resources Investigation Center, Beijing 100083, China
}

\begin{abstract}
Hylogger core scanning system is used to detailed scan shale gas drilling cores, obtaining visible-near infrared (spectral range 380nm-1100nm), short-wave infrared (spectral range $1100 \mathrm{~nm}-2500 \mathrm{~nm}$ ) spectral curves and high-definition core images. Taking Well weican 1 in the West Taikang Uplift in the South China North Basin as an example, based on the analysis of clay mineral types in the core of the target layer, it is judged to be an alkaline deposit environment rich in iron and magnesium with a temperature of about $130^{\circ} \mathrm{C}$. Combined with mineral information and core image, the core of the target layer is divided,mud shale is developed, the cumulative thickness exceeds $400 \mathrm{~m}$, the maximum single layer thickness reaches $38 \mathrm{~m}$, at the same time, the hydrocarbon absorption characteristics of the shale section are obvious, it shows a good prospect for shale gas in the region.
\end{abstract}

\section{Introduction}

\subsection{Geological background of WC-1}

Weican-1 well is a shale gas parameter well deployed in the western part of Taikang uplift, South Huabei basin. The western part of Taikang uplift is characterized by "North-South Division and east-west blocking". It is further divided into Tongxu uplift, central nose structure belt, Xuedian Weishi South sub sag, northern slope belt and Xinzheng uplift and other secondary structure ${ }^{[1]}$.

During the Benxi period of Late Carboniferous, the North China Plate was a flat monoclinal palaeotopography high in the northwest and low in the southeast. The sea water invaded from the northeast direction and deposited a set of sea-land interbedded strata. At the end of the Late Permian, the southern North China region was uplifted as a whole, and the paleo-terrain was high in the north and low in the south, and the sea water completely withdrew, and the climate changed from warm and humid to hot and arid. The basin entered the continental sedimentary development stage, and a set of red clastic rock formations with fluvial facies and fresh water limestone and gypsum were deposited ${ }^{[2,3,4,5]}$.

\subsection{Drilling stratigraphic information of WC-1}

Well weican1 encountered Quaternary,Neogene, Triassic System, Shiqianfeng Formation, upper Shihezi Formation, Lower Shihezi Formation, Permian Shanxi formation, Taiyuan formation, Carboniferous Benxi Formation and other strata from top to bottom. Shanxi Formation and Taiyuan Formation of Upper Paleozoic are the main target strata for shale gas development of well weican 1 (Fig. 1).

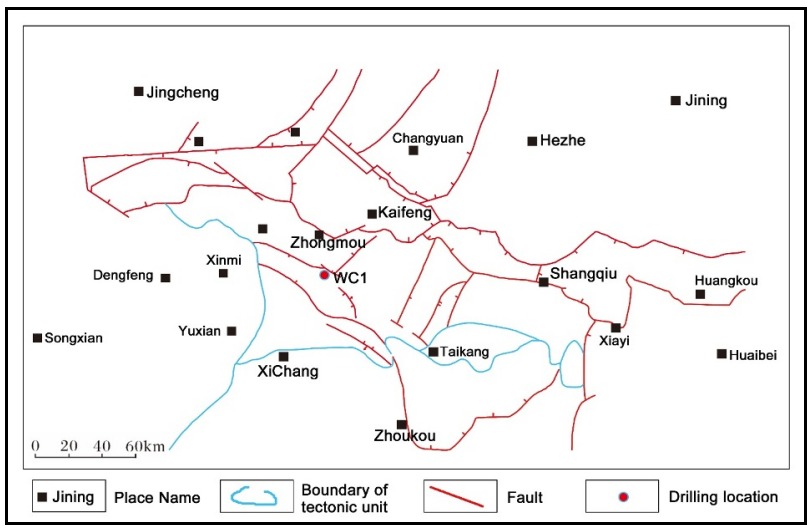

Fig. 1. Structural unit map of Taikang uplift area (From Liu Yongtao ${ }^{[6]}$, Modify).

\section{Analysis of hyperspectral information}

In the figure below, al-oh and chlorite show the change of absorption peak position and absorption intensity with depth, while kaolinite shows the change of absorption intensity with depth. According to the clay mineral identification map of well weican 1, al-oh absorption peak position is before $2212 \mathrm{~nm}$, and it is concentrated in $2198 \mathrm{~nm}-2205 \mathrm{~nm}$. It is distributed in the form of medium and high aluminum, with the largest

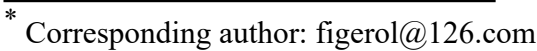




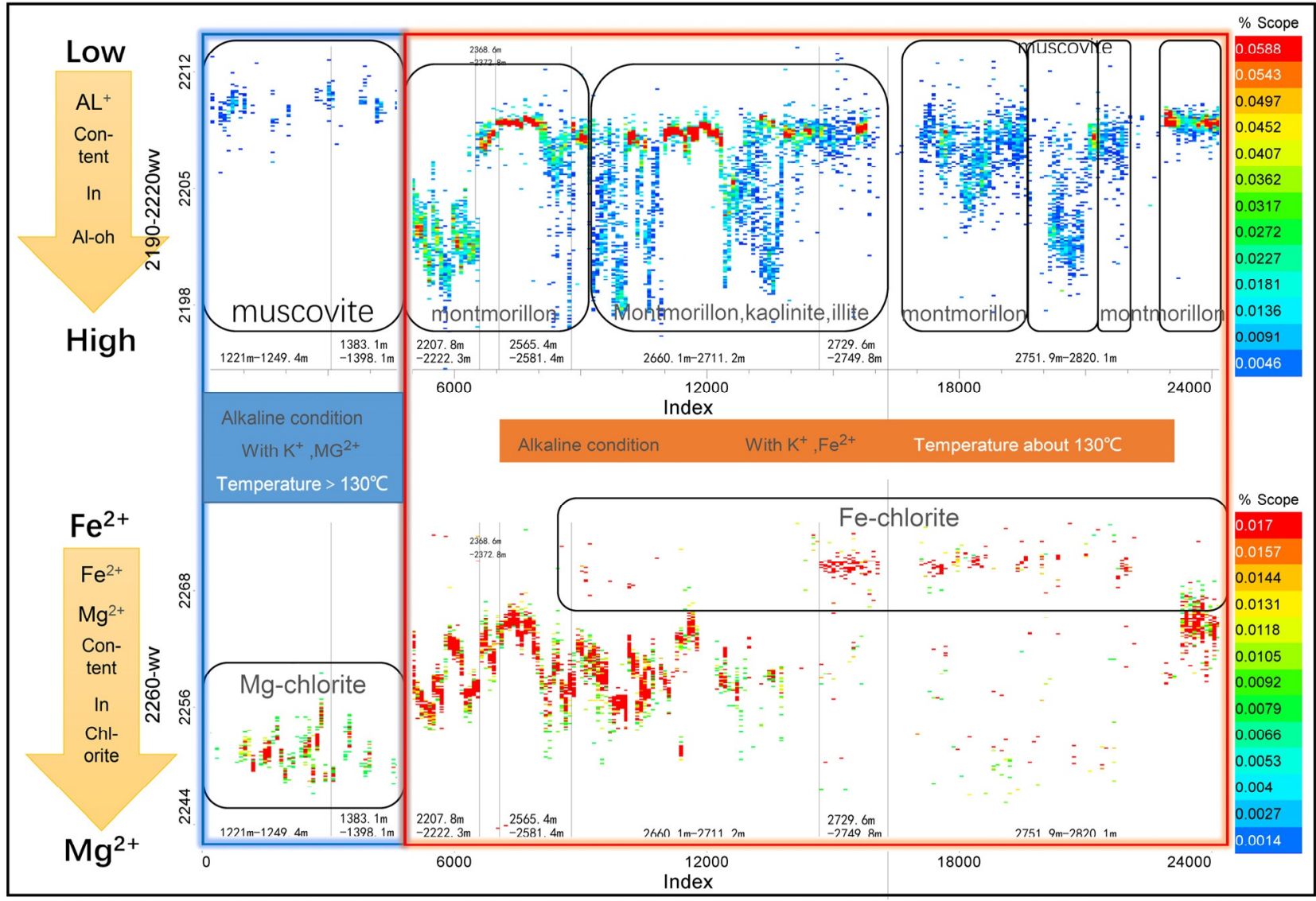

Fig. 2. Distribution of clay minerals in well weican 1.

absorption depth (red area in the figure) It is mainly

kaolinite and montmorillonite in other sections.

In the process of sedimentary diagenesis, with the deepening of burial depth and high temperature rise, montmorillonite has a tendency to transform into illite and chlorite, which is transformed into illite in the alkaline condition rich in potassium ${ }^{[7]}$, and chlorite in the alkaline environment rich in $\mathrm{Fe}$ and $\mathrm{Mg}$.

When the temperature is between $60^{\circ} \mathrm{C}$ and $130{ }^{\circ} \mathrm{C}$, montmorillonite is unstable and dehydrates, resulting in some interlayer collapses, resulting in lattice rearrangement and adsorption of alkaline cations. Mudstone continuously dehydrates and releases $\mathrm{Fe}$ and $\mathrm{Mg}$. Biotite and some $\mathrm{Fe}$ and $\mathrm{Mg}$ rich rock cuttings continuously hydrolyze and dissolve to provide $\mathrm{Fe}$ and $\mathrm{Mg}$. Flocculated $\mathrm{Fe}$ rich colloids also hydrolyze and dissolve during deposition, resulting in pore fluid in sandstone When the content of $\mathrm{Fe}$ and $\mathrm{Mg}$ ions in the pore fluid reaches a certain level, chlorite will precipitate from the alkaline pore water, enter the montmorillonite chlorite mixed layer stage, and then transform into chlorite $^{[8]}$.

It can be seen that the former part is dominated by Mg-chlorite, while the middle part is dominated by Fechlorite, and the content of magnesium hydroxyl group circulates from less-more-less.

\section{Lithology analysis of well WC-1}

\subsection{Hyperspectral lithology identification}

The Hyperspectral Information of the core provides mineral information, which can distinguish limestone and shale. Meanwhile, the signal-to-noise ratio of the spectrum can reflect the brightness of the lithology. The high signal-to-noise ratio is generally sandstone with bright tone; the general signal-to-noise ratio is mudstone shale with gray and gray black; the poor signal-to-noise ratio is generally dark core, such as carbonaceous and siliceous rock series.

The core high-definition image can directly reflect the color, shape and texture characteristics of the core, and can judge the lithology transformation, fracture, vein intrusion and other information.

Table 1. Hyperspectral Lithology Recognition Rules. (From Liu Pengfei ${ }^{[9]}$, Modify).

\begin{tabular}{|l|l|}
\hline Lithology & \multicolumn{1}{c|}{ Characteristic description } \\
\hline \multirow{3}{*}{ Gray } & $\begin{array}{l}\text { 2320-2340nm,6570-6630nm,11190- } \\
11320 \mathrm{~nm} \text { Obvious absorption peak. } \\
\text { The image shows uniform texture, grey } \\
\text { and gray. }\end{array}$ \\
\hline
\end{tabular}




\begin{tabular}{|c|c|}
\hline $\begin{array}{l}\text { Argilla- } \\
\text { ceous }\end{array}$ & $\begin{array}{l}2190-2220 \mathrm{~nm} \text { or } 2250-2260 \mathrm{~nm} \text { Obvious } \\
\text { absorption peak, } 2340-2380 \mathrm{~nm} \text { Secondary } \\
\text { absorption peak, } 9560-9600 \mathrm{~nm} \text { Obvious } \\
\text { absorption peak. } \\
\text { The image is uniform in color and texture. }\end{array}$ \\
\hline Sandy & $\begin{array}{l}2190-2220 \mathrm{~nm} 、 2340-2380 \mathrm{~nm} \text { absorption } \\
\text { peak, } 8240 \mathrm{~nm} 、 9080 \mathrm{~nm} 、 9250 \mathrm{~nm} \\
\text { Obvious absorption peak.The image is } \\
\text { variegated. }\end{array}$ \\
\hline $\begin{array}{l}\text { Silicifi- } \\
\text { cation } \\
\text { carbon- } \\
\text { ization }\end{array}$ & $\begin{array}{l}\text { Silica is shown as a smooth surface on the } \\
\text { image.Carbon is shown as black and } \\
\text { reflective on the image. }\end{array}$ \\
\hline $\begin{array}{l}\text { coal } \\
\text { seam }\end{array}$ & $\begin{array}{l}\text { Coal seams show fragmented and black } \\
\text { cores on the image. }\end{array}$ \\
\hline $\begin{array}{l}\text { Calcite- } \\
\text { vein }\end{array}$ & $\begin{array}{l}2340 \mathrm{~nm} \text { Strong absorption peak, } 6630 \mathrm{~nm} \text {, } \\
11320 \mathrm{~nm} \text { Obvious absorption peak. } \\
\text { The image shows white veins and bands. }\end{array}$ \\
\hline Dolor & $\begin{array}{l}2320 \mathrm{~nm} \text { Strong absorption peak, } 6570 \mathrm{~nm} \text {, } \\
11190 \mathrm{nmObvious} \text { absorption peak. } \\
\text { The image is uniform in texture, white, } \\
\text { gray or brown. }\end{array}$ \\
\hline $\begin{array}{l}\text { Quartz } \\
\text { vein }\end{array}$ & $\begin{array}{l}8240 \mathrm{~nm} \text { 、 } 9250 \mathrm{~nm} \text { Obvious absorption } \\
\text { peak, } 12500 \mathrm{~nm} \text { 、 } 12800 \mathrm{~nm} \text { Secondary } \\
\text { absorption peak. } \\
\text { The image shows white veins and bands } \\
\text { (similar to calcite veins in vision, } \\
\text { distinguished by thermal infrared } \\
\text { spectroscopy). }\end{array}$ \\
\hline Pyrite & $\begin{array}{l}900 \mathrm{~nm}-1100 \mathrm{~nm} \text { absorption peak. } \\
\text { The image is golden. }\end{array}$ \\
\hline Texture & $\begin{array}{l}\text { According to the change of particle size, } \\
\text { shape or color along the vertical direction, } \\
\text { the type of bedding and the filling of } \\
\text { fossils can be judged in the image. }\end{array}$ \\
\hline
\end{tabular}

\subsection{WC-1 lithology identification}

$1221 \mathrm{~m}-1249.45 \mathrm{~m}$ and $1383.1 \mathrm{~m} \sim 1398.1 \mathrm{~m}$, Triassic strata are mainly composed of light grey, brownish red siltstone and fine sandstone with purplish red mudstone and silty mudstone.

2207-2372.8m is the Upper Shihezi Formation of the Permian system. The lithology is mainly dark gray and gray-green silty mudstone, gray-green and light gray siltstone, gray-black and black mudstone. The top and bottom are mudstone, filled with calcite, and part of chloritization. The middle part is fine sandstone, siltstone, and thin layer of green silty mudstone with ash. The scanning core interval is $2207.28 \mathrm{~m} \sim 2222.28 \mathrm{~m}$. $2368.56 \mathrm{~m}$ to $2372.8 \mathrm{~m}$. 2565.44-2670.2m is the Lower Shihezi Formation of the Permian system. The lithology is mainly gray, dark gray mudstone, argillaceous siltstone, interspersed with gray fine sandstone, medium sandstone. The shale is developed in the form of interlayer with horizontal bedding, and the thickness of most single layers is less than $1 \mathrm{~m}$. Sandstones are developed at the top and bottom with cross-bedding in shape, and the middle and lower coal seams are developed.

2670.2-2742.4m is the Permian Shanxi Formation. The lithology is mainly composed of gray-black mudstone, carbonaceous mudstone and interbedded coal seam, interbedded with gray fine sandstone and medium sandstone. The upper member is mainly interbedded with shale, siltstone and medium-grained sandstone, while the lower member is continuously developed with horizontal bedding and core carbonization is visible.

$2742.4 \sim 2809 \mathrm{~m}$ is named the Taiyuan Formation of Permian system. The lithology is mainly gray black mudstone, gray limestone and gray fine sandstone, interbedded with multiple coal lines and partial interbedded with gray medium sandstone. The top and bottom are dark gray limestone, argillaceous filling, with thin layers of carbonaceous, pinnate and dendritic strips, filled with calcite. The headquarters is gray-black carbonaceous mudstone, horizontal bedding, interbedded with multilayer thin coal line, miscellany siltstone, limestone, and a small amount of pyrite.

$2809 \mathrm{~m}-2821.23 \mathrm{~m}$ is the Carboniferous Benxi Formation, mainly composed of gray-dark gray aluminous mudstone and gray-black carbonaceous mudstone. Grey-dark gray aluminous and carbonaceous mudstone, massive structure, higher carbonaceous content in the upper part, lower, uniform color in the upper part, uneven color in the lower part, more oolitic in the local area.

\subsection{Lithologic distribution of WC-1}

Lithology identification of cores from Well Wecan 1 shows that the Upper Paleozoic mud shale is developed. The accumulated thickness is over $400 \mathrm{~m}$, and the maximum single thickness is $38 \mathrm{~m}$. Among them, the thickness of Shangshihezi Formation mud shale is over $160 \mathrm{~m}$, the thickness of Xiashihezi Formation mud shale is over $100 \mathrm{~m}$, the thickness of Shanxi Formation mud shale is over $45 \mathrm{~m}$, and the thickness of Taiyuan Formation mud shale is over $30 \mathrm{~m}$.

Mud shale with thickness greater than $10 \mathrm{~m}$ appears more frequently, and the continuous thickness of mud shale interlayer in sandstone is between $20-50 \mathrm{~m}$.

The hydrocarbon absorption characteristics are extracted from each well section(Fig. 3). The comprehensive lithologic combination shows that the shale gas in this area has a good prospect.

\section{4 conclusion}

Using visible light to near infrared and short-wave infrared spectrum curve, identify the core of the hydrocarbon content and clay minerals, carbonate 
minerals and silicate minerals and iron oxide mineral combination of information and its change, can infer the diagenetic temperature and thermal maturity of these on the oil and gas exploration has guiding significance to the information, at the same time, combining with core image color, texture, contrast, brightness information of lithology can be performed quickly identify and concluded that the sedimentary environment; It provides a strong basis for the determination of the strong area of hydrocarbon generation.

The lithology of Qianfeng Formation in Well Wc-1 is mainly sandstone, and the clay minerals are mica

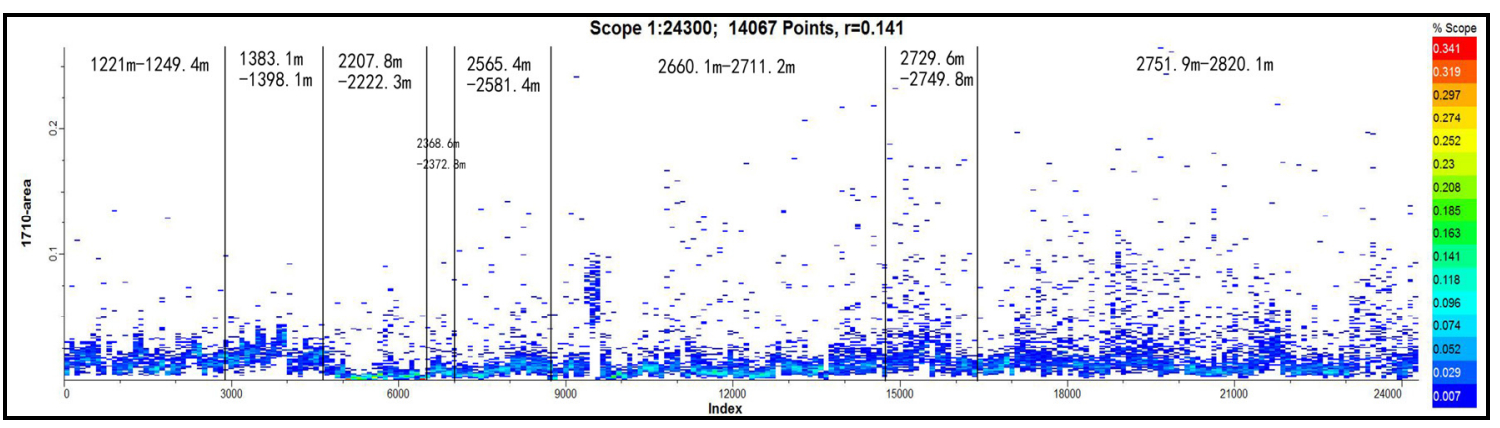

Fig. 3. Distribution of absorption intensity of $-\mathrm{CH}$

and chlorite. The clay minerals of Shihezi Formation and the middle and upper Shanxi Formation are montmorillonite, kaolinite and ferromagnesite chlorite, which reflects the alkaline environment where the deposition temperature is lower than $130^{\circ} \mathrm{C}$ and rich in ferromagnesite ions. The clay minerals in the lower Shanxi Formation and the lower Taiyuan Formation are montmorillonite and ferrochlorite, and the alkaline environment is rich in iron ions. The montmorillonite itself has a large specific surface area. At the same time, montmorillonite can adsorb a large amount of organic matter, especially interlayer organic matter, which also increases the total surface ratio of the source rock to a certain extent and is more conducive to the adsorption of shale gas ${ }^{[10]}$.

The shale of Upper Paleozoic Upper Shihezi Formation, Lower Shihezi Formation, Shanxi Formation and Taiyuan Formation are well developed. The accumulated thickness of the shale of the lower member of Shanxi Formation and the middle and upper member of Taiyuan Formation is large. These intervals are the main intervals for the development of high-quality source rocks.

\section{References}

1. BH. Zheng, The Key Techonogy Research of Digital Instrument for Rock Core scanning. Jilin University. Jilin. (2010)

2. GH.Hu, TP.Zhao, YY.Zhou, et al. MesoNeoproterozoic sedimentary formation in the southern margin of the North China Craton and its geological implications. Acta Petrologica Sinica.29(7) : 2491 - 2507(2013)

3. QF.Xie, LF.Zhou, Liu,XH. et al. Analysis of reservoir forming conditions in Well South 12 of Zhoukou Depression, South North China Basin. Petroleum Geology and Engineering. 22(5): 14-17. (2008)

4. YX.Lin, CZ.Zhu, CJ.Zhao, et al. Lithofacies paleogeographic characteristics in the Late Triassic in the North China area. Lithologic Reservoirs. 28(5): 82-90. (2016)

5. JB.Du, JC.Tian, MX.He, et al. Influential factors of Upper Paleozoic reservoirs in the south of North China. Journal of Chengdu University of Technology(Science \& Technology Edition). 39 (5): 496-501. (2012)

6. YT.Liu, The thermal anomaly features of north of the southern north china basin and its adjacent areas and its formation evolution. Northwest University. Xi'an.14-15. (2009)

7. SH.Tang, EP.Fan, Methane adsorption characteristics of clay minerals in organic-rich shales[J].Journal of China Coal Society. 9(8):1700-1706. (2014)

8, XK.Zhang, YF.Cai, CX.Fan, Simulation study on the conversion of montmorillonite to chlorite by "chloritization".The 17th Annual Conference of the Chinese Society of Mineralogy Petrology and Geochemistry.Hangzhou.pp.97(2019)

9. PF. Liu, YJ. Zhao, HD Zhang, et al. Application of hyperspectral technology in shale gas exploration.Second Target Recognition and Artificial Intelligence Summit Forum. 11427-3k (2020).

10. YL.Li, JG.Cai, Effect of smectite illitization on shale gas occurrence in argillaceous source rocks. Petroleum Geology and Experiment. 000(003):352358. (2014) 